Article

\title{
Cross-Cyclotrimerization with Two Nitriles as a Synthetic Pathway to Unsymmetrically 3,3'-Disubstituted bis(Tetrahydroisoquinolines)
}

\author{
Aneta Kadlč́́ková ${ }^{1}$ and Martin Kotora ${ }^{1,2, *}$
}

1 Department of Organic and Nuclear Chemistry, and Center for Structural and Synthetic Application of Transition Metal Complexes, Faculty of Science, Charles University in Prague, Hlavova 8, 128 43 Praha 2, Czech Republic

2 Institute of Organic Chemistry and Biochemistry, Academy of Sciences of the Czech Republic, Flemingovo nám. 2, 16610 Praha 6, Czech Republic

* Author to whom correspondence should be addressed; E-mail: kotora@natur.cuni.cz

Received: 10 July 2009; in revised form: 31 July 2009 / Accepted: 3 August 2009 /

Published: 10 August 2009

\begin{abstract}
Microwave assisted $\mathrm{CpCo}(\mathrm{CO})_{2}$ catalyzed cross-cyclotrimerizations of 1,7,9,15hexadecatetrayne with two different nitriles to give unsymmetrically substituted bis(tetrahydroisoquinolines) was studied. The reaction proceeded with a range of alkyl and aryl nitriles with reasonable isolated yields.
\end{abstract}

Keywords: cyclotrimerization; cobalt; microwave heating; pyridines

\section{Introduction}

Lewis base catalyzed processes constitute a large group of reactions that has been extensively used in organic synthesis and especially in asymmetric catalysis [1]. Among Lewis bases that have recently attracted considerable attention are pyridine $N$-oxides and their congeners. For example, they are able to strongly activate halosilanes via Lewis base-acid interaction to such an extent that halosilanes react with various functional groups. In this respect, enantioselective catalytic allylation of aldehydes have been intensively studied [2-8]. A number of various $N$-oxides [9-20], $N, N$-dioxides [21-27] and even $N, N, N$-trioxides [28] based on heterocyclic compounds with pyridine ring have been synthesized for this purpose. 
We have recently demonstrated that microwave irradiation-enhanced Co-complex catalyzed $[2+2+2]$-cross-cyclotrimerization of diynes with nitriles can be conveniently used for simple and expedient synthesis of various bipyridines. Their oxidation, usually by MPCBA, and resolution into enantiomers yielded the corresponding chiral bipyridine $N, N$-dioxides [29-33]. The compounds catalyzed asymmetric allylation of aldehydes in up to $87 \%$ ee. In our last report we showed that the cyclotrimerization of 1,7,9,15-hexadecatetrayne with two different nitriles, benzonitrile and $(R)$ tetrahydrofurancarbonitrile, furnished unsymmetrically substituted bis(tetrahydroisoquinoline) in $28 \%$ isolated yield, along with the symmetric derivative (20\% isolated yield). Its further oxidation afforded two diastereoisomeric bis(tetrahydroisoquinoline) $N, N$ '-dioxides that catalyzed enantioselective allylation of aldehydes [34]. This result provided us with impetus to study potential application of cobalt-complex catalyzed cross-cyclotrimerization of 1,7,9,15-hexadecatetrayne (1) with various nitriles as a pathway to unsymmetrically substituted bis(tetrahydroisoquinolines).

\section{Results and Discussion}

The microwave assisted cyclotrimerization of alkynes with nitriles offers several advantages in comparison with standard thermal conditions. Among these are, for example, reduced reaction times from hours to minutes, reactants are thus exposed to high reaction temperatures for shorter periods of time reducing possibility of thermal decomposition, and also the use of lower boiling point solvents such as THF, which allows easier separation of products [35-40].

For the study of cross-cyclotrimerization of 1,7,9,15-hexadecatetrayne (1) with various nitriles the previously used conditions were applied: $\mathrm{CpCo}(\mathrm{CO})_{2}(20 \mathrm{~mol} \%)$, nitrile $\mathrm{R}^{1}-\mathrm{CN}$ (1 equiv.), nitrile $\mathrm{R}^{2}$ $\mathrm{CN}$ (1-20 equiv.), THF as solvent. The reactions were carried out in microwave reactor (microwave irradiation $300 \mathrm{~W}$, reaction time $25 \mathrm{~min}$ ). A series of cross-cyclotrimerization reactions between two different nitriles with 1,7,9,15-hexadecatetrayne (1) in various molar ratios was carried out with varied success (Scheme 1).

Scheme 1. Co-cyclotrimerization of tetrayne 1 with nitriles 2 and 3.

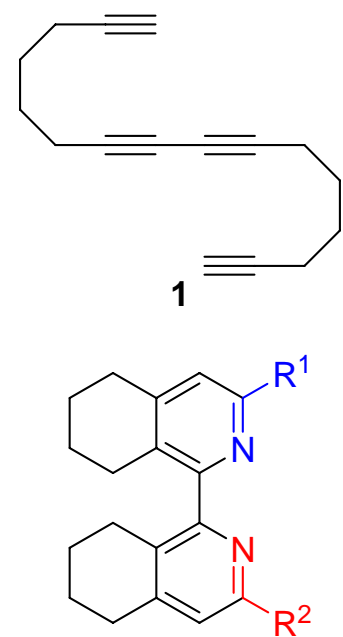

4

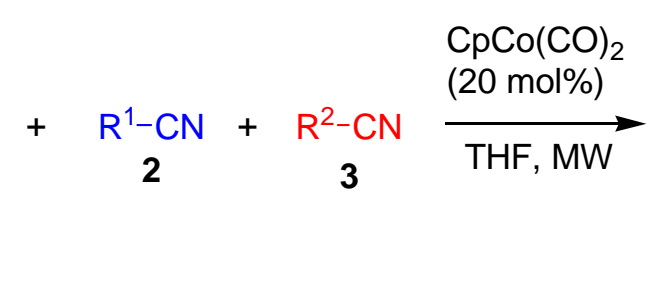<smiles>[R]c1cc2c(c(-c3nc([R])cc4c3CCCC4)n1)CCCC2</smiles>

5<smiles>[R]c1cc2c(c(-c3nc([R])cc4c3CCCC4)n1)CCCC2</smiles>

6 
In all cases the desired products of cross-cyclotrimerization of $\mathbf{1}$ with two different nitriles $\mathbf{2}$ and $\mathbf{3}$ unsymmetrically substituted bis(tetrahydroisoquinolines) $\mathbf{4}$ - were formed. The reaction was always accompanied by the formation of varying amounts of symmetrically substituted bis(tetrahydroisoquinolines) $\mathbf{5}$ and/or $\mathbf{6}$, the products of cyclotrimerization of $\mathbf{1}$ with $\mathbf{2}$ or $\mathbf{3}$. Some of the most representative examples are given in Table 1.

Table 1. Cross-cyclotrimerization of tetrayne $\mathbf{1}$ with two nitriles $\mathbf{2}$ and $\mathbf{3}$.

\begin{tabular}{|c|c|c|c|c|c|c|c|}
\hline Entry & $\mathbf{R}^{1}-\mathbf{C P}$ & $\mathbf{R}^{2}-\mathbf{C N}$ & & $\mathbf{R}^{1} / \mathbf{R}^{\mathbf{a}}$ & Yield $(\%)^{b} 4$ & Yield $(\%)^{b} 5$ & Yield $(\%)^{b} 6$ \\
\hline 1 & $\mathrm{C}_{6} \mathrm{H}_{5}$ & $\mathrm{CH}_{3}$ & $3 a$ & $1 / 1$ & $\mathbf{4 a}, 10$ & $\mathbf{5 a}, 30$ & 0 \\
\hline 2 & & & & $1 / 10$ & 25 & 10 & 0 \\
\hline 3 & & & & $1 / 20$ & 25 & 10 & 0 \\
\hline 4 & $\mathrm{C}_{6} \mathrm{H}_{5}$ & $4-\mathrm{MeOC}_{6} \mathrm{H}_{4}$ & $3 \mathbf{b}$ & $1 / 1$ & $4 b, 23$ & $\mathbf{5 a}, 15$ & 0 \\
\hline 5 & & & & $1 / 10$ & 28 & 10 & 0 \\
\hline 6 & $\mathrm{C}_{6} \mathrm{H}_{5}$ & $2-\mathrm{C}_{5} \mathrm{H}_{4} \mathrm{~N}^{\mathrm{e}}$ & $3 \mathbf{c}$ & $1 / 1$ & $4 c, 20$ & $\mathbf{5 a}, 10$ & 0 \\
\hline 7 & & & & $1 / 5$ & 28 & 2 & 0 \\
\hline 8 & $\mathrm{C}_{6} \mathrm{H}_{5}$ & $\mathrm{THF}^{* \mathrm{c}}$ & 3d & $1 / 1$ & $\mathbf{4 d}, 28$ & $\mathbf{5 a}, 10$ & 0 \\
\hline 9 & & & & $1 / 10$ & 24 & 10 & 0 \\
\hline 10 & $\mathrm{CH}_{3}$ & $3,4,5-(\mathrm{MeO})_{3} \mathrm{C}_{6} \mathrm{H}_{4}$ & $3 \mathbf{e}$ & $1 / 1$ & $4 e, 20$ & traces & $6 e, 9$ \\
\hline 11 & & & & $10 / 1$ & 28 & 0 & 5 \\
\hline 12 & $\mathrm{CH}_{3}$ & $4-\mathrm{CF}_{3} \mathrm{C}_{6} \mathrm{H}_{4}$ & $3 f$ & $1 / 1$ & 4f, 12 & 0 & 6f, 30 \\
\hline 13 & & & & $10 / 1$ & 20 & 0 & 15 \\
\hline 14 & $\mathrm{CH}_{3}$ & $4-\mathrm{ClC}_{6} \mathrm{H}_{4}$ & $3 g$ & $1 / 1$ & $\mathbf{4 g}, 22$ & 0 & $6 g, 10$ \\
\hline 15 & & & & $10 / 1$ & 27 & 0 & 5 \\
\hline 16 & $\mathrm{CH}_{3}$ & $\mathrm{THF}^{* \mathrm{c}}$ & 3d & $1 / 1$ & $4 h, 16^{d}$ & 0 & $6 \mathbf{h}, 16^{\mathrm{d}}$ \\
\hline 17 & & & & $10 / 1$ & $16^{\mathrm{d}}$ & $\mathbf{5 b}, 16^{\mathrm{d}}$ & $3^{\mathrm{d}}$ \\
\hline
\end{tabular}

Thus the cross-cyclotrimerization of benzonitrile (2) with acetonitrile (3a, 1/1 2/3a ratio) gave preferentially symmetrical product 5a (Entry 1), the change of the nitrile ratio to $1 / 10$ resulted in the preferential formation of $\mathbf{4 a}$ (25\% isolated yield) which was accompanied by a small amount of $\mathbf{5 a}$ $(10 \%)$ (Entry 2). The formation of $\mathbf{6 a}$ was not detected. Further change of the nitrile ratio did not affect the reaction outcome (Entry 3 ). The analogical results were obtained also in other cases. Thus cross-cyclotrimerization of benzonitrile (2) and 4-methoxybenzonitrile (3b, 1/10 2/3b ratio) gave $4 \mathbf{b}$ in $28 \%$ isolated yield along with $10 \%$ of $5 \mathbf{a}$ (Entry 5). The formation of $\mathbf{4 c}$ was achieved in $28 \%$ isolated yield (1/5 2/3c ratio) and $5 \mathbf{a}$ was formed in just $2 \%$ yield (Entry 7). Finally benzonitrile (2) and (R)tetrahydrofurancarbonitrile (2d) were cross-cyclotrimerized to yield the corresponding $\mathbf{4 d}$ in $28 \%$ isolated yield. Unlike in the previous cases, the best result was obtained when both nitriles were used in 1/1 molar ratio (compare Entries 8 and 9). In none of the cases was the formation of 6a-6d detected.

Then combination of acetonitrile (3a) and other nitriles was also studied. The best results for cyclotrimerization of 3a with nitriles 3e-3g giving the highest yields of the corresponding bis(tetrahydroisoquinolines) $\mathbf{4 e - 4 g}(28,20$, and 27\% yields, respectively) occurred when the molar ratios of $\mathbf{3 a} / \mathbf{3 e}, \mathbf{3 a} / \mathbf{3 f}$, and $\mathbf{3 a} / \mathbf{3 g}$ were $10 / 1$ (Entries 11, 13, and 15). On the other hand, for the 
reactions of $\mathbf{3 a}$ with nitrile $\mathbf{3 d}$ the optimal ratio of $\mathbf{3 a} / \mathbf{3 d}$ was $1 / 1$ (Entry 16). The formation $\mathbf{5 b}$ was not observed under these conditions.

It should be emphasized that the cross-cyclotrimerization proceeded only under microwave irradiation. Carrying out the reaction under standard thermal condition $\left(130^{\circ} \mathrm{C}, 24-48 \mathrm{~h}\right)$ or attempts to facilitate the cyclotrimerization by visible light irradiation gave rise to intractable reaction mixtures.

Attempts to carry out the cyclotrimerization sequentially, i.e. to cyclotrimerize tetrayne $\mathbf{1}$ with one nitrile, isolate the expected intermediate (1-diynyltetrahydroisoquinoline), and then to carry out the second cyclotrimerization with another nitrile, also failed. The first reaction under the above mentioned conditions usually proceeded with low selectivity for the monocyclotrimerization (only up to $30 \%$ ) and low yields $(\sim 10 \%)$, regardless of the nitrile used, making the whole process uneconomical. Carrying out the monocyclotrimerization under less forcing conditions by using another catalytic system, e.g. $\mathrm{CoCl}_{2} \cdot 6 \mathrm{H}_{2} \mathrm{O}, \mathrm{Zn}$, dppe $[41,42]$, did not meet the expectations either. Although the reaction proceeded exclusively to yield 1-diynyltetrahydroisoquinolines, the yields did not exceed in $10 \%$. The use of catalysts based on other transition metals ( $\mathrm{Rh}, \mathrm{Ru}$ ) did not promote the cyclotrimerization.

\section{Experimental}

\section{General}

All solvents, unless otherwise stated, were used as obtained. THF was distilled from sodium and benzophenone under Ar. All other reagents were obtained from commercial sources. ${ }^{1} \mathrm{H}$ - and ${ }^{13} \mathrm{C}$ NMR spectra were recorded on a Varian UNITY $300\left({ }^{1} \mathrm{H}\right.$ at $300 \mathrm{MHz},{ }^{13} \mathrm{C}$ at $\left.75 \mathrm{MHz}\right)$ as solutions in $\mathrm{C}_{6} \mathrm{D}_{6}$. Chemical shifts are given in $\delta$-scale, coupling constants $J$ are given in Hz. Mass spectra were recorded on a LTQ Orbitrap XL. Infrared spectra were recorded on a FTIR Nicolet avatar Drift $\mathrm{KBr}$ and are reported in wave numbers $\left(\mathrm{cm}^{-1}\right)$. Fluka 60 silica gel was used for flash chromatography. TLC was performed on silica gel $60 \mathrm{~F}_{254}$-coated aluminum sheets (Merck). All reactions were carried out under an argon atmosphere using flasks or in microwave reactor Biotage Initiator. Hexadeca-1,7,9,15tetrayne (1) was prepared according to the previously reported method [43].

\section{General procedure for cross-cyclotrimerization}

$\mathrm{R}^{1} \mathrm{CN}(0.48 \mathrm{mmol}), \mathrm{R}^{2} \mathrm{CN}(4.8 \mathrm{mmol})$ and $\mathrm{CpCo}(\mathrm{CO})_{2}(18 \mathrm{mg}, 0.1 \mathrm{mmol})$ were added under atmosphere of argon to a solution of hexadeca-1,7,9,15-tetrayne (1, $100 \mathrm{mg}, 0.48 \mathrm{mmol})$ in dry and degassed THF $(3 \mathrm{~mL})$ contained in a vial. Then the vial was placed into the microwave oven and irradiated for $25 \mathrm{~min}(300 \mathrm{~W})$ (during the process temperature and pressure reached $180{ }^{\circ} \mathrm{C}$ and 20 barr, respectively). Unreacted nitriles were then removed under reduced pressure and column chromatography of the residue on silica gel using the indicated eluent systems yielded the products.

5,6,7,8-Tetrahydro-1-(5,6,7,8-tetrahydro-3-methylisoquinolin-1-yl)-3-phenylisoquinoline (4a). Eluent: $3 / 1$ hexane/EtOAc; yield: $40 \mathrm{mg}$ (25\%) of the title compound as a viscous colorless liquid and $30 \mathrm{mg}$ $(10 \%)$ of symmetrical benzonitrile substituted product 5a. Compound 4a: ${ }^{1} \mathrm{H}-\mathrm{NMR}: \delta 1.44-1.49(\mathrm{~m}$, $8 \mathrm{H}), 2.44-2.48(\mathrm{~m}, 4 \mathrm{H}), 2.51(\mathrm{~s}, 3 \mathrm{H}), 2.61-2.66(\mathrm{~m}, 4 \mathrm{H}), 6.59(\mathrm{~s}, 1 \mathrm{H}), 7.19(\mathrm{~s}, 1 \mathrm{H}), 7.24-7.29(\mathrm{~m}, 3 \mathrm{H})$, 
8.17-8.20 (m, 2H); ${ }^{13} \mathrm{C}-\mathrm{NMR}: \delta 23.2(2 \mathrm{C}), 23.9,24.0,24.8,26.8,27.0,30.2,30.5,120.4,123.3,127.9$ (2C), 128.2, 128.5, 129.2, 129.4, 130.8, 141.0, 147.4, 148.0, 154.0, 154.7, 158.7, 159.3; IR (THF) $v$ 696, 1069, 1430, 1590, 1722, 2858, 2933, $3085 \mathrm{~cm}^{-1}$; ESI-MS m/z (\% relative intensity) $355\left(\mathrm{M}^{+}\right.$, 100), 377 (15); HR-ESI calculated for $\mathrm{C}_{25} \mathrm{H}_{26} \mathrm{~N}_{2} 355.2169$ found 355.2169.

5,6,7,8-Tetrahydro-1-(5,6,7,8-tetrahydro-3-phenylisoquinolin-1-yl)-3-(4-methoxyphenyl)iso-quinoline

(4b). Eluent: 3/1 hexane/EtOAc; yield: $60 \mathrm{mg}$ (28\%) of the title compound as a viscous colorless liquid and $20 \mathrm{mg}(10 \%)$ of symmetrical benzonitrile substituted product 5a. Compound 4b: ${ }^{1} \mathrm{H}-\mathrm{NMR}$ : $\delta 1.48-1.50(\mathrm{~m}, 8 \mathrm{H}), 2.51-2.53(\mathrm{~m}, 4 \mathrm{H}), 2.69-2.71(\mathrm{~m}, 4 \mathrm{H}), 3.31(\mathrm{~s}, 3 \mathrm{H}), 6.91-6.93(\mathrm{~m}, 2 \mathrm{H}), 7.18-7.20$ $(\mathrm{m}, 1 \mathrm{H}), 7.19-7.21(\mathrm{~m}, 1 \mathrm{H}) ; 7.27-7.32(\mathrm{~m}, 3 \mathrm{H}), 8.21-8.24(\mathrm{~m}, 4 \mathrm{H}) ;{ }^{13} \mathrm{C}-\mathrm{NMR}: \delta 23.2,23.3,23.9,24.0$, 27.1 (2C), 30.5 (2C), 55.5, 115.0, 119.8, 120.5, 127.9 (2C), 129.2 (4C), 129.5 (2C), 130.3, 131.1, 133.6, 141.0, 148.1 (2C), 153.9, 154.0, 159.0, 159.2, 161.4; IR (THF) v 694, 835, 1030, 1172, 1247, 1307, 1416, 1451, 1514, 1550, 1589, 1608, $2931 \mathrm{~cm}^{-1}$; ESI-MS m/z (\% relative intensity) $447\left(\mathrm{M}^{+}\right.$, 100), 448 (36), 469 (8), 893 (50), 915 (50), 916 (35), 917 (15); HR-ESI calculated for $\mathrm{C}_{30} \mathrm{H}_{30} \mathrm{~N}_{2} \mathrm{O}$ 447.2431 found 447.2426 .

5,6,7,8,-Tetrahydro-1-(5,6,7,8-tetrahydro-3-phenylisoquinolin-1-yl)-3-(pyridin-2-yl)isoquino-line (4c). Eluent: $1 / 1$ hexane/EtOAc; yield: $55 \mathrm{mg}$ (28\%) of the title compound as a viscous colorless liquid and $4 \mathrm{mg}(2 \%)$ of symmetrical benzonitrile substituted product 5a. Compound 4c: ${ }^{1} \mathrm{H}-\mathrm{NMR}$ : $\delta$ 1.44-1.46 (m, 8H), 2.43-2.64 (m, 8H), 6.84-6.85 (m, 1H), 7.18-7.21, (m, 3H), 7.26-7.32 (m, 2H), 8.19-8.29 (m, $3 \mathrm{H}), 8.57-8.58(\mathrm{~m}, 1 \mathrm{H}), 9.52(\mathrm{~s}, 1 \mathrm{H}) ;{ }^{13} \mathrm{C}-\mathrm{NMR}: \delta 22.0,22.2,22.8,22.9,26.1,29.3,29.4,30.0,119.7$, 123.1, 126.9 (2C), 128.3 (2C), 128.5, (2C), 130.0, 130.8, 133.7, 135.0, 139.8, 147.3, 147.5, 148.4, 149.6, 150.5, 153.1, 157.7, 158.4; IR (THF) v 689, 751, 806, 1024, 1160, 1430, 1588, 2855, 2922, $3036 \mathrm{~cm}^{-1}$; ESI-MS m/z (\% relative intensity) $418\left(\mathrm{M}^{+}, 100\right), 440$ (61); HR-ESI calculated for $\mathrm{C}_{29} \mathrm{H}_{27} \mathrm{~N}_{3} 418.2269$, found 418.2278 .

3-[(R)-Tetrahydrofuran-2-yl]-3'-phenyl-(5,5',6,6',7,7',8,8'-octahydro-l,l'-biisoquinoline)

(4d).

Eluent: $5 / 1$ hexane/EtOAc; yield: $56 \mathrm{mg}(28 \%)$ of the title compound as a viscous colorless liquid and $20 \mathrm{mg}(20 \%)$ of symmetrical product 5a. Compound 4d: ${ }^{1} \mathrm{H}-\mathrm{NMR}: \delta 1.36-1.68(\mathrm{~m}, 11 \mathrm{H}), 2.08-2.14$ (m, 1H), 2.19-2.26 (m, 1H), 2.46-2.68 (m, 7H), 3.74-3.80 (m, 1H), 3.95-4.0 (m, 1H), 5.23 (t, J=7Hz; 1H), 7.15-7.19 (m, 1H), 7.25-7.29 (m, 3H), $7.4(\mathrm{~s}, 1 \mathrm{H}), 8.16-8.19(\mathrm{~m}, 2 \mathrm{H}) ;{ }^{13} \mathrm{C}-\mathrm{NMR}: \delta 23.2(2 \mathrm{C})$, 24.0 (2C), 26.7, 27.0, 27.1, 30.4, 30.5, 34.0, 69.5, 82.4, 120.3, 120.5, 128.2, 128.6 (2C), 129.2 (2C), 130.4, 131.0, 140.9, 148.0, 148.1, 153.9, 158.4, 159.1, 160.1; IR (THF) v 699, 961, 1069, 1432, 1722, 2877, 2937, $3292 \mathrm{~cm}^{-1}$; ESI-MS m/z (\% relative intensity) $411\left(\mathrm{M}^{+}, 100\right), 412$ (31), 433 (27); HR-ESI calculated for $\mathrm{C}_{28} \mathrm{H}_{30} \mathrm{~N}_{2} \mathrm{O}+\mathrm{H}^{+}$411.2431, found 411.2421.

5,6,7,8-Tetrahydro-1-(5,6,7,8-tetrahydro-3-(3,4,5-trimethoxyphenyl)isoquinolin-1-yl)-3-methyl-isoquinolne (4e). Eluent: $3 / 1$ hexane/EtOAc; yield: $60 \mathrm{mg}(28 \%)$ of the titled compound as a viscous colorless liquid and $2 \mathrm{mg}$ (5\%) of symmetrical 3,4,5-trimethoxybenzonitrile substituted product $6 \mathbf{6}$. Compound 4e: ${ }^{1} \mathrm{H}-\mathrm{NMR}: \delta$ 1.46-1.51 (m, 8H), 2.42-2.65 (m, 11H), $3.42(\mathrm{~s}, 6 \mathrm{H}), 3.88(\mathrm{~s}, 3 \mathrm{H}), 6.56$ $(\mathrm{s}, 1 \mathrm{H}), 7.42(\mathrm{~s}, 1 \mathrm{H}), 7.53(\mathrm{~s}, 2 \mathrm{H}) ;{ }^{13} \mathrm{C}-\mathrm{NMR}: \delta 23.3,23.9,24.0,24.7,26.8,26.9,30.2,30.5,56.6(2 \mathrm{C})$, 61.2, 106.1, 120.3, 123.4, 128.6 (2C), 129.0 (2C), 130.5, 136.4, 141,4, 147.4, 148.0, 154.3, 155.0, 155.1, 158.7, 159.3; IR (THF) v 853, 1068, 1127, 1228, 1430, 1554, 2858, 2934, 1584, $1721 \mathrm{~cm}^{-1}$; 
ESI-MS $\mathrm{m} / \mathrm{z} \quad\left(\% \quad\right.$ relative intensity) $445 \quad\left(\mathrm{M}^{+}, 100\right), 467 \quad(33)$; HR-ESI calculated for $\mathrm{C}_{28} \mathrm{H}_{32} \mathrm{~N}_{2} \mathrm{O}_{3} 445.2486$ found 445.2476 .

1-(3-(4-(Trifluoromethyl)phenyl)-5,6,7,8-tetrahydroisoquinolin-1-yl)-5,6,7,8-tetrahydro-3-methylisoquinoline (4f). Eluent: 3/1 hexane/EtOAc; yield: $40 \mathrm{mg} \mathrm{(20 \% )}$ of this product as a viscous colorless liquid and $30 \mathrm{mg}(15 \%)$ of symmetrical 4-(trifluoromethyl)benzonitrile substituted product $\mathbf{6 f}$. Compound 4f: ${ }^{1} \mathrm{H}-\mathrm{NMR}: \delta$ 1.46-1.50 (m, 8H), 2.45-2.48 (m, 4H), $2.51(\mathrm{~s}, 3 \mathrm{H}), 2.58-2.64(\mathrm{~m}, 4 \mathrm{H}), 6.60$ $(\mathrm{s}, 1 \mathrm{H}), 7.16(\mathrm{~s}, 1 \mathrm{H}), 7.47(\mathrm{~m}, 2 \mathrm{H}), 8.00(\mathrm{~m}, 2 \mathrm{H}) ;{ }^{13} \mathrm{C}-\mathrm{NMR}: \delta 23.1,23.2,23.7,23.8,24.0,24.7,26.8$, 27.0, 30.1, 30.4, 32.6, 120.8, 123.5, 126.3, 126.4, 127.7, 128.1, 129.2, 132.0, 144.1, 148.0, 148.3, 152.2, 154.8, 158.3, 159.6; IR (THF) v 848, 1015, 1068, 1123, 1161, 1323, 1432, 1591, 2858, $2928 \mathrm{~cm}^{-1}$; ESI-MS m/z (\% relative intensity) $423\left(\mathrm{M}^{+}, 100\right), 445$ (58); HR-ESI calculated for $\mathrm{C}_{26} \mathrm{H}_{25} \mathrm{~N}_{2} \mathrm{~F}_{3} 445.2486$ found 445.2476.

1-(3-(4-Chlorophenyl)-5,6,7,8-tetrahydroisoquinolin-1-yl)-5,6,7,8-tetrahydro-3-methylisoquinoline (4g). Eluent: $3 / 1$ hexane/EtOAc; yield: $50 \mathrm{mg}(27 \%)$ of this product as a viscous colorless liquid and 9 $\mathrm{mg}(5 \%)$ of symmetrical 4 -chlorobenzonitrile substituted product $\mathbf{6 g}$. Compound $4 \mathrm{~g}:{ }^{1} \mathrm{H}-\mathrm{NMR}: \delta 1.43-$ 1.49 (m, 8H), 2.44-2.47 (m, 4H), 2.51 (s, 3H), 2.57-2.63 (m, 4H), 6.59 (s, 1H), $7.12(\mathrm{~s}, 1 \mathrm{H}), 7.21-7.24$ $(\mathrm{m}, 2 \mathrm{H}), 7.89-7.92(\mathrm{~m}, 2 \mathrm{H}) ;{ }^{13} \mathrm{C}-\mathrm{NMR}: \delta 23.2,23.3,23.9,24.0,24.7,26.8,26.9,30.1,30.4,120.2$, 123.4, 128.8 (2C), 129.2 (2C), 129.6, 131.2, 135.3, 139.3, 147.5, 148.1, 152.6, 154.8, 158.5, 159.4; IR $(\mathrm{THF}) \vee 834,1012,1304,1431,1492,1592,2857,2932 \mathrm{~cm}^{-1}$; ESI-MS m/z (\% relative intensity) 389 $\left(\mathrm{M}^{+}, 100\right), 391$ (36); ESI-MS m/z (\% relative intensity) $389\left(\mathrm{M}^{+}, 100\right), 391$ (36); HR-ESI calculated for $\mathrm{C}_{25} \mathrm{H}_{25} \mathrm{~N}_{2} \mathrm{Cl} 389.1779$ found 389.1779 .

5,6,7,8-Tetrahydro-1-(5,6,7,8-tetrahydro-3-methylisoquinolin-1-yl)-3-(tetrahydrofuran-2-yl)isoquinoline (4h). Eluent: EtOAc; yield: $52 \mathrm{mg}(32 \%)$ of the mixture of this product and the symmetrical $(R)$-tetrahydrofurancarbonitrile substituted product $\mathbf{6 h}$ in the ratio of 1:1. Compound $\mathbf{4 h}$ : ${ }^{1} \mathrm{H}-\mathrm{NMR}: \delta$ 1.36-1.66 (m, 12H), 2.01-2.10 (m, 2H), 2.18-2.29 (m, 2H), 2.38-2.50 (m, 7H), 3.74-3.79 $(\mathrm{m}, 1 \mathrm{H}), 3.91-3.97(\mathrm{~m}, 1 \mathrm{H}), 5.15-5.19(\mathrm{~m}, 1 \mathrm{H}), 6.56(\mathrm{~s}, 1 \mathrm{H}), 7.36(\mathrm{~s}, 1 \mathrm{H}) ;{ }^{13} \mathrm{C}-\mathrm{NMR}: \delta 22.9,(2 \mathrm{C})$, 23.7, 24.3, 26.3, 26.5, 26.6, 29.8, 30.1, 30.5, 33.6, 69.1, 82.0, 119.8, 199.9, 129.8, 130.0, 147.5, 147.6, $158.0,158.3,159.7,159.8$.

\section{Conclusions}

In conclusion, we have demonstrated that $\mathrm{CpCo}(\mathrm{CO})_{2}$ catalyzed cross-cyclotrimerization of 1,7,9,15-hexadecatetrayne with two different nitriles under microwave irradiation can be a convenient method for synthesis of unsymmetrically substituted bis(tetrahydroisoquinolines). Although the isolated yields of the unsymmetrical products did not exceed $30 \%$, this shortcoming is counterweighed by the simplicity and expeditiousness of the cross-cyclotrimerization method and also by the fact that sequential two step cyclotrimerization cannot be applied due to low selectivity and thermal instability of the starting tetrayne. Last but not least, it also should taken into the account that during two catalytic cycles six new bonds are formed. 


\section{Acknowledgements}

Authors gratefully acknowledge financial support from the Czech Science Foundation (Grant No. 203/08/0350) and Ministry of Education of the Czech Republic to the Center for Structural and Synthetic Application of Transition Metal Complexes (Project Nos. LC06070, MSM0021620857, and Z40550506).

\section{References and Notes}

1. For recent review, see: Denmark, S.E.; Beutner, G.L. Lewis Base Catalysis in Organic Synthesis. Angew. Chem. Int. Ed. 2008, 47, 1560-1638.

2. Chelucci, G.; Thummel, R.P. Chiral 2,2‘-Bipyridines, 1,10-Phenanthrolines, and 2,2‘:6“,2“‘Terpyridines: Syntheses and Applications in Asymmetric Homogeneous Catalysis. Chem Rev. 2002, 102, 3129-3170.

3. Malkov, A.V.; Kočovský, P. Chiral Bipyridine Derivatives in Asymmetric Catalysis. Curr. Org. Chem. 2003, 7, 1737-1757.

4. Chelucci, G.; Murineddu, G.; Pinna, G.A. Chiral pyridine $N$-oxides: useful ligands for asymmetric catalysis. Tetrahedron Asymmetry 2004, 15, 1373-1389.

5. Kočovský, P.; Malkov, A.V. From Transition Metals To Organocatalysis, Russ. Chem. Bull. Int. Ed. 2004, 53, 1806-1812.

6. Orito, Y.; Nakajima, M. Chiral Base-Catalyzed Aldol Reaction of Trimethoxysilyl Enol Ethers: Effect of Water as an Additive on Stereoselectivities. Synthesis 2006, 1391-1401.

7. Malkov, A.V.; Kočovský, P.; Chiral N-Oxides In Asymmetric Catalysis. Eur. J. Org. Chem. 2007, 29-36.

8. For general review on allylation of the carbonyl group see: Denmark, S.; Catalytic Enantioselective Addition of Allylic Organometallic Reagents to Aldehydes and Ketones. Chem. Rev. 2003, 103, 2763-2793.

9. Malkov, A.V.; Orsini, M.; Pernazza, D.; Muir, K.W.; Langer, V.; Kočovský, P. Chiral 2,2‘Bipyridine-Type $\mathrm{N}$-Monoxides as Organocatalysts in the Enantioselective Allylation of Aldehydes with Allyltrichlorosilane. Org. Lett. 2002, 4, 1047-1049.

10. Malkov, A.V.; Bell, M.; Vassieu, M.; Bugatti, V.; Kočovský, P.; New pyridine-derived N-oxides as chiral organocatalysts in asymmetric allylation of aldehydes. J. Mol. Catal. 2003, 196, 179-186.

11. Malkov; A.V.L.; Dufková, L.; Farrugia L.; Kočovský, P. Quinox, a Quinoline-Type N-Oxide, as Organocatalyst in the Asymmetric Allylation of Aromatic Aldehydes with Allyltrichlorosilanes: The Role of Arene-Arene Interactions. Angew. Chem., Int. Ed. 2003, 42, 3674-3676.

12. Malkov, A.V.; Bell, M.; Castelluzzo, F.; Kočovský, P. METHOX: A New Pyridine N-Oxide Organocatalyst for the Asymmetric Allylation of Aldehydes with Allyltrichlorosilanes. Org. Lett. 2005, 7, 3219-3222.

13. Pignataro, L.; Benaglia, M.; Annunziata, R.; Cinquini, M.; Cozzi, F. Structurally Simple Pyridine $\mathrm{N}$-Oxides as Efficient Organocatalysts for the Enantioselective Allylation of Aromatic Aldehydes. J. Org. Chem. 2006, 71, 1458-1463.

14. García-Flores, F.; Flores-Michel, K. S.; Juristi, E. Asymmetric allylation of $N$-benzoylhydrazones promoted by novel $C_{2}$-symmetric bis-sulfoxide organocatalysts. Tetrahedron Lett. 2006, 47, 8235-8238. 
15. Chelucci, G.; Baldino, S.; Pinna, G.A.; Benaglia, M.; Buffa, L.; Guizzetti, S. Chiral pyridine $N$ oxides derived from monoterpenes as organocatalysts for stereoselective reactions with allyltrichlorosilane and tetrachlorosilane. Tetrahedron 2008, 64, 7574-7582.

16. Muller, C.A.; Hoffart, T.; Holbach, M.; Reggelin, M. Pyridyl- $N$-oxide Substituted hellicaly Chiral Poly(methacrylate)s in asymmetric Organocatalysis. Macromolecules 2005, 38, 5375-5380.

17 Pignataro, L.; Benaglia, M.; Cinquini, M.; Cozzi, F.; Celentano, G. Readily available pyridineand quinoline- $N$-oxides as new organocatalysts for the enantioselective allylation of aromatic aldehydes with allyl(trichloro)silane. Chirality 2005, 17, 396-403.

18. Chelucci, G.; Belmonte, N.; Benanglia, M.; Pignataro, L. Enantioselective allylation of aldehydes with allyltrichlorosilane promoted by new chiral dipyridylmethane $N$-oxides. Tetrahedron Lett. 2007, 48, 4037-4041.

19. Simonini, S.; Benaglia, M.; Pignataro, L.; Guizzetti, S.; Celentano, G. A New Class of Chiral Lewis Basic Metal-Free Catalysts for Stereoselective Allylations of Aldehydes. Synlett 2008, 1061-1065.

20 Chai, Q.; Sung, C.; Sun, Z.; Ma, Y.; Ma, C.; Dai, Y.; Andrus, M.B. Asymmetric allylation of aldehydes with allyltrichlorosilane using aza-paracyclophane-oxazoline- $N$-oxide catalysts. Tetrahedron Lett. 2006, 47, 8611-8615.

21. Nakajima, N.; Saito, M.; Shiro, M.; Hashimoto, S. (S)-3,3‘-Dimethyl-2,2‘-biquinoline $N, N^{`}-$ Dioxide as an Efficient Catalyst for Enantioselective Addition of Allyltrichlorosilanes to Aldehydes. J. Am. Chem. Soc. 1998, 120, 6419-6420.

22. Nakajima, N.; Saito, M.; Hashimoto, S. One-pot Enantioselective Synthesis of optically Active Homoallylic Alcohols from Allyl Halides. Chem. Pharm. Bull. 2000, 48, 306-307.

23. Nakajima, N.; Saito, M.; Hashimoto, S. Selective synthesis of optically active allenic and homopropargylic alcohols from propargyl chloride. Tetrahedron Asymmetry 2002, 13, 2449-2452.

24. Shimada, T.; Kina, A.; Ikeda, S.; Hayashi, T. A Novel Axially Chiral 2,2'-Bipyridine N,N'Dioxide. Its preparation and Use for Asymmetric Allylation of Aldehydes with Allyl(trichloro)silane as a Highly Efficient Catalyst. Org. Lett. 2002, 4, 2799-2801.

26. Shimada, T.; Kina, A.; Hayashi, T. A Novel Axially Chiral 2,2'-Bipyridine $N, N^{\prime}$-Dioxide. Its Preparation and Use for Asymmetric Allylation of Aldehydes with Allyl(trichloro)silane as a Highly Efficient Catalyst. J. Org. Chem. 2003, 68, 6329-6337.

27. Kina, A.; Shimada, T.; Hayashi, T. A New Approach to Axially Chiral Bipyridine $N, N^{\prime}$-Dioxides Bearing Aromatic Substituents and their Use for Catalytic Asymmetric Allylation of Aldehydes with Allyl(trichloro)silane. Adv. Synth. Catal. 2004, 346, 1169-1174.

28. Wong, W.L.; Lee, C.S.; Leung, H.K.; Kwong, H.L. The first series of chiral 2,2`: $6^{\prime}, 2^{\prime \prime}$-terpyridine tri- $N$-oxide ligands for Lewis base-catalyzed asymmetric allylation of aldehydes. Org. Biomol. Chem. 2004, 2, 1967-1969.

29. Hrdina, R.; Stará, I.G.; Dufková, L.; Mitchel, S.; Císařová, I.; Kotora, M. Synthesis of atropoisomeric pyridines via cobalt-catalyzed cocyclotrimerization of diynes with benzonitrile. Tetrahedron 2006, 62, 968-976.

30 Hrdina, R.; Kadlčíková, A.; Valterová, I.; Hodačová, J.; Kotora, M. An easy route to atropoisomeric bipyridine $N, N^{\prime}$-dioxides and allylation of aldehydes. Tetrahedron Asymmetry 2006, 17, 3185-3191. 
31. Hrdina, R.; Valterová, I.; Hodačová, J.; Kotora, M. A Simple Approach to Unsymmetric Atropoisomeric Bipyridine $N, N^{s}$-Dioxides and Their Application in Enantioselective Allylation of Aldehydes. Adv. Synth. Catal. 2007, 349, 822-826.

32. Hrdina, R.; Dračínský, M.; Valterová, I.; Hodačová, J.; Císařová, I.; Kotora, M. New Pathway to $C_{2}$-Symmetric Atropoisomeric Bipyridine $N, N^{x}$-Dioxides and Solvent Effect in Enantioselective Allylation of Aldehyde. Adv. Synth. Catal. 2008, 350, 1449-1456.

33. For application of alkyne-nitrile cyclotrimerization in organic synthesis, see: Turek, P.; Kotora, M. Synthesis of pyridines by [2+2+2]-cyclotrimerization of alyknes with nitriles. Targ. Heterocyclic Syst. 2009, 13, in press.

34. Kadlčíková, A.; Hrdina, R.; Valterová, I.; Kotora, M. Simple and Fast Synthesis of New Axially Chiral Bipyridine $N, N$ '-Dioxide for Highly Enantioselective Allylation of Aldehydes. Adv. Synth. Catal. 2009, 351, 1279-1283.

35. Zhou, Y.; Porco, J.A.; Snyder, J.K. Synthesis of 5,6,7,8-Tetrahydro-1,6-naphthyridines and Related Heterocycles by Cobalt-Catalyzed [2 + 2 + 2] Cyclizations. Org. Lett. 2007, 9, 393-395.

36. Young, D.D.; Deiters, A. A General Approach to Chemo- and Regioselective Cyclotrimerization Reactions. Angew. Chem. Int. Ed. 2007, 47, 5187-5190.

37. Zou, Y.; Young, D.D.; Cruz-Montanez, A.; Deiters, A. Synthesis of Anthracene and Azaanthracene Fluorophores via [2+2+2] Cyclotrimerization Reactions Org. Lett. 2008, 10, 4661-4664.

38. McIver, A.; Young, D.D.; Deiters, A. A general approach to triphenylenes and azatriphenylenes: total synthesis of dehydrotylophorine and tylophorine. Chem. Commun. 2008, 4750-4752.

39. Turek, P.; Hocek, M.; Pohl, R.; Klepetářová, B.; Kotora, M. Cobalt-Induced Synthesis of 6(Pyridin-2-yl)purines by Microwave-Enhanced [2+2+2] Cyclotrimerization. Eur. J. Org. Chem. 2008, 3335-3343.

40. Zhou, Y.; Beeler, A.B.; Cho, S.; Wang, Y.; Franzblau, S.G.; Snyder, J. K. Library Synthesis Using 5,6,7,8-Tetrahydro-1,6-naphthyridines as Scaffolds. J. Comb. Chem. 2008, 10, 534-540.

41. Kase, K.; Goswami, A.; Ohtaki, K.; Tanabe, E.; Saino, N.; Okamoto, S.; On-Demand Generation of an Efficient Catalyst for Pyridine Formation from Unactivated Nitriles and $\alpha, \omega$-Diynes Using $\mathrm{CoCl}_{2}-6 \mathrm{H}_{2} \mathrm{O}$, dppe, and Zn. Org. Lett. 2007, 9, 931-934.

42. Goswami, A.; Ohtaki, K.; Kase, K.; Ito, T.; Okamoto, S. Synthesis of Substituted 2,2'-Bipyridines and $2,2^{*}: 6^{\prime}, 2^{\prime \prime}$-Terpyridines by Cobalt-Catalyzed Cycloaddition Reactions of Nitriles and $a, \infty-$ Diynes with Exclusive Regioselectivity. Adv. Synth. Catal. 2008, 350, 143-152.

43. Sondheimer, F.; Amiel, Y. Unsaturated Macrocyclic Compounds. Synthesis of Cyclohexadeca1,3,9,11-tetrayne by a Novel Cyclization Reaction. J. Am. Chem. Soc. 1957, 79, 5817-5820.

Sample Availability: Samples of the compounds are available from the authors.

(C) 2009 by the authors; licensee Molecular Diversity Preservation International, Basel, Switzerland. This article is an open-access article distributed under the terms and conditions of the Creative Commons Attribution license (http://creativecommons.org/licenses/by/3.0/). 